\title{
Los nuevos movimientos sociales y el movimiento de mujeres en El Salvador
}

\author{
María Candelaria Navas \\ Universidad de El Salvador
}

RESUMEN: En este artículo se aporta al estudio de los llamados 'nuevos movimientos sociales' a partir del significado del movimiento de mujeres en El Salvador. La autora hace un abordaje sistemático de la historia de dicho movimiento y aporta un balance crítico acerca del mismo.

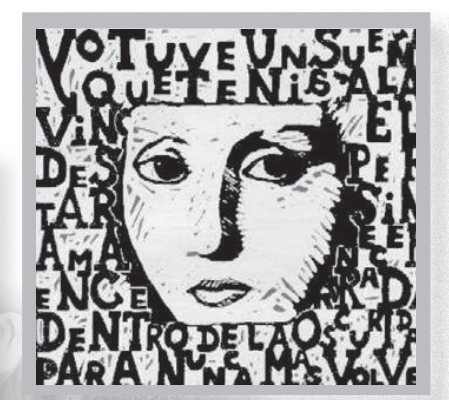

ABSTRACT: In this essay there is an important contribution to the studies on the so-called 'New Social Movements', from the scope of the women's movement in El Salvador. The author makes a systematic study on the history of such movement and gives a critical analysis about it. 
os movimientos sociales, como forma de acción colectiva, se han construido y manifestado a lo largo de la historia moderna como expresión del conflicto social entre el sistema dominante y aquellos a quienes domina. Dan cuenta del desarrollo de la conciencia de grupos, sectores, cuerpos sociales. Todos los enfoques de análisis coinciden en que los movimientos sociales parten de la necesidad de explicar el conflicto.

Sin embargo estos grupos sociales devienen en movimiento social, únicamente cuando construyen identidades, tiene una visión a futuro de una situación distinta y actúan ante sus adversarios, rompiendo los límites, para conseguir cambios sociales.

En buena parte del siglo XX los movimientos sociales fueron analizados desde la perspectiva socio-política como expresión de los conflictos de clase; su accionar y sus luchas, como parte de su enfrentamiento con el sistema. Sin embargo, su acción se subordina en gran medida a las líneas preferenciales de los partidos políticos y la acción política tenía una dirección por conquistar el poder. Así, el sistema solamente podría ser cambiado cuando se lograra la toma del poder para transformar de raíz ese sistema y construir uno en el que las reivindicaciones de los sectores populares fueran definitivamente conquistadas y resueltas.

Al referirnos a los nuevos movimientos sociales (NMS) debemos considerar el origen de este fenómeno en Europa en los años sesenta, vinculado a los Ilamados derechos pos-materiales y a la nueva relación que se establece entre lo público y lo privado. En el primer caso se refiere a la defensa del medio ambiente, los derechos de los consumidores y los movimientos por la calidad de vida. En el segundo caso se hace referencia principalmente al feminismo y a los movimientos por la defensa de las minorías, éstos buscan o persiguen colocar a nivel público temas e identidades que estaban circunscritos al ámbito de lo privado.

En los últimos veinticinco años, una serie de fenómenos sociales y políticos han convulsionado la región latinoamericana y del Caribe: movimientos de liberación, revoluciones triunfantes, etc. concibiéndose como temas de análisis y estudio de los científicos sociales. Precisamente la irrupción en la escena pública de las sociedades latinoamericanas de los llamados nuevos movimientos sociales, en referencia a los movimientos de liberación feminista, el movimiento ecologista, movimiento de la teología de la liberación y pacifista, al movimiento de consumidoras y consumidores, que han ido desplazando al movimiento obrero, campesino de la izquierda tradicional.

Emprendiendo así el cuestionamiento del enfoque ideológico, se desarrolla una corriente que se ha dado en llamar "postmodernismo", que reivindica el fin de las 
ideologías y explica el surgimiento de nuevos movimientos sociales en oposición a los enfoques ideológicos, como reivindicando hacer cambios, hacer transformaciones, particularmente en las esferas cultural y jurídico-legal de la acción generalmente pacífica.

Durante los años 80, como sabemos, se gestaron en El Salvador y en el resto de los países centroamericanos los Ilamados Movimientos Populares, entendidos éstos como aquellas acciones colectivas que hicieron suyo un proyecto contrahegemónico, que planteaban demandas específicas en el marco de la conquista por una sociedad justa; así, los maestros se organizaron en ANDES 21 DE JUNIO, los estudiantes universitarios en AGEUS, los campesinos en FECCAS-UTC, los obreros en FUSS, etc. Es hasta en los años 90, a mediados, y después de la firma de los Acuerdos de Paz, cuando asistimos a la explosión de nuevos movimientos y a la paulatina transformación de aquellos de los años 60-70, ya que en las nuevas condiciones se da otro nivel de los conflictos, por supuesto innovadoras y nuevas formas de acción política.

En esta nueva fase del accionar de los movimientos sociales expresados en el país, podemos destacar el movimiento de mujeres, el de los vendedores informales, el ecologista, el de consumidoras y consumidores, el de los trabajadores del Estado: los médicos de la red pública, los empleados del Ministerio de Hacienda, por ejemplo.
Dentro de la sociología moderna, connotados teóricos de estos nuevos movimientos sociales como Alberto Melucci, Alain Touraine, Manuel Castells, Cohen y Arato, Mardones, entre otros, nos permiten acercarnos a una demarcación a partir del estudio más directo de los actuales movimientos sociales. Para Melucci, un movimiento social es una forma de acción colectiva que apela a la solidaridad, lo que sugiere que tenga capacidad para compartir en el marco de la acción colectiva, sus miembros se reconocen unos a otros como similares, como actores que tienen los mismos problemas, porque pertenecen a un determinado segmento social. Por otra parte, un movimiento social hace evidente un conflicto social.

Para Alain Touraine, "la noción de movimiento social sólo es útil si permite poner en evidencia la existencia de un tipo muy específico de acción colectiva, aquel por el cual una categoría social, siempre particular, pone en cuestión una forma de dominación social, a la vez particular y general, e involucra en ella valores, orientaciones generales de la sociedad que comparte con su adversario, para privarlo de tal modo de legitimidad".

Los movimientos sociales, por lo tanto, son cuestionadores de una forma de dominación socio-cultural. Un movimiento social puede romper los límites del sistema en que se producen y reproducen como expresiones colectivas de la sociedad civil, de tal manera que 
los movimientos sociales se construyen en relación o en correlación del contexto de lo político y lo económico en donde se expresa la correlación de fuerzas sociales. Su objeto es modificar esa realidad, y pueden plantearlo desde una perspectiva estructural, incluyendo una perspectiva coyuntural. Pueden tener distinta extensión en el tiempo, pueden desaparecer, no solamente porque se estructuran en una coyuntura determinada, por ejemplo oposición a un acto de privatización, a la construcción del periférico, etc. sino porque aunque se planeen a más largo plazo no logren construir una sólida identidad colectiva.

También pueden actuar en un espacio pequeño, un barrio, un municipio, o llegar a nivel nacional, regional e incluso mundial (por ejemplo: el movimiento globalifóbico o antiglobalización). Dependiendo de sus objetivos pueden cuestionar el sistema, estructuralmente hablando, o alguna de sus partes.

Podemos mencionar algunos rasgos comunes generales de los nuevos movimientos sociales:

a. Su base social trasciende la estructura de clases. El origen social de los participantes es difuso y diverso, no provienen de ningún grupo sector o clase social en particular; la cohesión se logra en base a valores o temáticas compartidas y su composición se explica por la edad, el género, la orientación sexual o la pertenencia a un sector o profesión.
En el caso salvadoreño, si bien es compartida en tanto que las convocatorias a la movilización social no tienen como eje articulador la estructura de clases en sentido estricto, también es cierto que por la historia política salvadoreña, los actuales movimientos sociales tienen una fuerte connotación de clase, no tanto por los discursos, pero sí por su composición.

b. No se identifican con una ideología política en particular, ni tampoco la ideología constituye un elemento unificador. Tienden más bien a caracterizarse por el pluralismo de ideas y valores, con una orientación pragmática, es el sentido de "ser", de nombrarse a sí mismos de forma individual y colectiva lo que permite construir las identidades en los movimientos sociales. En El Salvador, dadas las precarias condiciones de vida y la historia política de las organizaciones sociales, se abre una mayor presencia a las ideologías políticas.

c. Buscan una ampliación de los sistemas de participación en decisiones de interés colectivo, es decir, mayores oportunidades de participación política y civil, otorgándoles gran importancia a las dimensiones civiles de la sociedad frente a las vinculadas al Estado. Los actores que participan en los movimientos sociales toman como objetivo los aspectos sociales más que la 
economía o el Estado y plantean asuntos o demandas relativas a la democratización de las estructuras de la vida cotidiana dando prioridad a formas de comunicación e identidad colectiva

d. Son heterogéneos en sus formas de acción y organización y a veces la diversidad en las demandas puede llegar a traslaparse. En general se centran en aspectos íntimos de la vida humana o bien reivindican cuestiones de la vida cotidiana que no están basadas en intere- ses estrictamente económicos, ni de clase.

e. Desarrollan formas de organización un tanto descentralizadas, abiertas y democráticas, con formas de liderazgos flexibles, cambiantes, generando organizaciones específicas: concertaciones, grupos de presión, etc.

f. Tratan de mantener cierto distanciamiento del modelo tradicional de organización política, que se traduce en autonomía en relación a los sistemas políticos.

\section{El movimiento de mujeres en El Salvador}

$\mathrm{P}$ ara abordar el movimiento de mujeres en El Salvador, haré una breve referencia al marco histórico que le antecede y del cual se nutre. Obligadamente debo hablar de sus fundamentos: me refiero en concreto al movimiento feminista mundial.

Los orígenes del feminismo como filosofía y como movimiento son diversos, varían desde la resistencia a las prácticas opresivas hasta la lucha por la igualdad de derechos. Surge en el mundo occidental y ha estado influenciado por conceptos y prácticas socialistas, luchas antiimperialistas y nacionalistas en el tercer mundo y por los retos de las mujeres negras, tanto en Estados Unidos como en Europa. Por lo tanto, ha dejado de ser un fenómeno exclusivamente occidental.
Viene de la "Ilustración" europea desde el siglo XVIII, el "Siglo de las luces", cuando toma su primer gran impulso, con una serie de nuevos modos e ideas que suelen reunirse como amor cortés que sirve para dar modelos de autoestima y conducta a las mujeres de las castas nobles con discursos misóginos y ginofóbicos, ya que por un lado se exaltan las virtudes y cualidades femeninas y por otro se exponen los defectos y hasta boberías de las mismas, exponiendo como marco común que las mujeres han de estar bajo la autoridad masculina. En Francia, durante la Revolución francesa, surgen expresiones de resistencia que son acalladas hasta con la guillotina. Tal es el caso de Olimpia de Gouges, que escribió La declaración de los derechos de la mujer y la ciudadana en 1791. Sin 
embargo, la obra fundacional del feminismo es Vindicación, editada en 1792, de Mary Wollstonecraft, que es un alegato pormenorizado contra la exclusión de las mujeres del campo completo de los bienes y derechos que diseña la teoría política de Juan Jacobo Rousseau. Para algunas autoras, el feminismo ilustrado configura la llamada "primera ola del feminismo".

La segunda ola del feminismo gira alrededor del movimiento sufragista y de lucha por los derechos políticos iguales para la mujer. Se desarrolla a finales del siglo XIX y comienzos del XX. El sufragismo fue un movimiento de agitación internacional, que se inició en Inglaterra y Estados Unidos. Estuvo presente en todas las sociedades industriales y tomó dos objetivos concretos: el derecho al voto y los derechos educativos, y consiguió ambos en un período de ochenta años.

En los años 60 apareció una tercera ola que vio el surgimiento de movimientos para la mujer en casi todos los países del mundo occidental, e inició una serie de cambios en los valores y formas de vida que todavía se siguen produciendo. Las mujeres constataron que los derechos políticos -incluido el votose tenían, los derechos educativos se ejercían, las profesiones se iban ocupando, pero todavía no se había conseguido una posición a la par de los hombres. Se iniciaron cambios legislativos, laborales, en los medios de comunicación, la sexualidad, la salud, la pareja, sintetizados en la lucha por los Derechos Humanos de las Mujeres.

En los últimos quince años en El Salvador, y en otros países de América Latina con más antelación, se ha dado un movimiento amplio de mujeres que incluye, como lo propone Virginia Vargas Valente: “(...) la vertiente feminista, la vertiente popular y la vertiente de las mujeres que actúan de los espacios formales-tradicionales de organización y acción política (...). La presencia de cada una de las mencionadas vertientes ha impactado en los distintos ámbitos de la vida en estos países. Uno de ellos ha sido el de la organización y acción política, el de la vertiente popular y el feminista en El Salvador.

Para las autoras del libro Movimiento de mujeres en Centroamérica, estas diferencias se presentan así: "Distinguimos al movimiento de mujeres como aquél que reúne mujeres independientemente de sus demandas, en tanto el feminista es aquél que se reúne en función de luchar contra la subordinación de la mujer, siendo portador de una utopía. En el caso centroamericano, el movimiento feminista comparte con el movimiento de mujeres la característica de la búsqueda de los cambios que mejoren la condición y/o posición de las mujeres en la sociedad y aporta a éste un componente ideológico que ahonda en las causas de la subordinación y apunta a la construcción de propuestas alternativas susceptibles de ser compartidas por diversas expresiones del movimiento" (Aguilar: 1998: 14). 
Consideramos que en el nuevo contexto y accionar de los movimientos sociales, el movimiento de mujeres y sus diferentes expresiones constituyen parte del mismo. Sin embargo, desde una perspectiva histórica, al relacionar dicho movimiento con el accionar de las organizaciones de mujeres encontramos tres momentos:

a) Las organizaciones de mujeres ligadas al movimiento obrero en el marco de la lucha de clases.

b) Las organizaciones de mujeres apoyando el proyecto contrahegemónico, en el marco de los "movimientos populares revolucionarios "(Menjívar: 1985).

c) Las organizaciones con reivindicaciones propias o de género, que es el momento en que surgen las demandas específicas del ser mujer.

Las organizaciones ubicadas en los dos primeros momentos están colocadas en la consideración de que los sectores subalternos se constituían a partir de su determinación e identidad de clase. Consecuentemente, las mujeres y/o sus organizaciones debían "sumar fuerzas" a otros movimientos, a otras reivindicaciones de carácter global. Las transformaciones estructurales, a ese nivel, resolverían todas las formas de opresión, incluida la de género. Las salvadoreñas se integraron a estas luchas sociales, aproximadamente hasta 1986 momento en que se funda la primera organi- zación que incorpora la dimensión de género.

Para el estudio y análisis de las principales organizaciones existentes en El Salvador y tomando como base la propuesta de periodización que Morena Herrera presenta en el estudio para el caso salvadoreño en el libro ya mencionado Movimiento de mujeres en Centroamérica, al que le he agregado dos períodos más uno antes y otro al final. Mi propuesta es la siguiente:

Primer período: De la segunda mitad del siglo XIX, con el antecedente de la creación de la Universidad de El Salvador (1841) y el parcial acceso de las mujeres a la educación, hasta la segunda mitad de la década de los años 50 del siglo XX con la creación en 1956 de la Organización Fraternidad de Mujeres Salvadoreñas, ligada al movimiento obrero del Partido Comunista Salvadoreño, creado en 1930. En este período, en 1930, se auto- proclama candidata a la presidencia de la república Prudencia Ayala cuando aún no se había legalizado el voto femenino. Este se aprobó en septiembre de 1950.

El proceso de reconocimiento de los derechos políticos de las mujeres en El salvador tuvo características específicas y particulares que lo diferenciaron del de la mayoría de los demás países de la región.

1. La inexistencia de un movimiento sufragista, como consecuencia del aislamiento cultural y de la represión social que los 
regímenes autoritarios impusieron en el país desde comienzos del siglo XX.

2. Una activa participación de las mujeres en todos los movimientos sociales y políticos de la historia política del país.

3. El interés de los regímenes autoritarios de promover el otorgamiento de estos derechos a las mujeres, con el objetivo de capitalizar a su favor el voto femenino.

Segundo período: De 1957 a 1975. La creación de Fraternidad de Mujeres cierra y abre este período que se caracteriza por el surgimiento de las primeras organizaciones exclusivamente femeninas, cuyo énfasis era sectorial, aunque elaboraron reivindicaciones y estrategias de acción propias ligadas a la esfera doméstica. Las mujeres se integran a las diferentes organizaciones que conforman el movimiento popular e incluyen sus demandas de clase dentro de la plataforma de las demandas populares. El inicio de la Década de la Mujer 1975-1985, instaurada por las Naciones Unidas, cierra esta período y abre el siguiente, dado que esta iniciativa da pautas y ejerce cierto tipo de influencia y presión a nivel gubernamental y a las mujeres les abre ventanas y motivaciones para dar los saltos que les permita trascender la esfera doméstica y dar forma a lo que será a futuro el movimiento de mujeres y feminista salvadoreño.
Tercer período: De 1975 a 1985. "Primera oleada"1 de organizaciones femeninas, muchas de ellas conformadas en el exilio y otras dentro del país, para apoyar la lucha popular. La característica principal de estas organizaciones de mujeres es la nula reivindicación de género en sus objetivos, demandas o plataformas. Este período coincide con el auge del conflicto armado y las migraciones masivas, dentro y fuera del país, por razones políticas. También es la apertura de la creación de organizaciones que trascenderán el análisis de clase para integrar el análisis de género.

Cuarto Período: De 1986 a 1989. "Segunda oleada" de organizaciones que, provenientes de organizaciones políticas de izquierda, comienzan a analizar "la problemática de la mujer", lejos de asumirse feministas. Todavía la guerra civil se encontraba en su accionar. Justamente con el inicio del período vemos aparecer el Instituto de Investigación, Promoción y Desarrollo de la Mujer (IMU) desde la sociedad civil, cuyas fundadoras son mujeres del Partido Comunista. Cierra el período la ofensiva guerrillera de noviembre de 1989 en la cual es asesinada la fundadora del IMU, Norma Virginia Guirola de Herrera y se abren los cauces para un cierre negociado a la guerra civil.

Quinto período: De 1990 a 1993. "Tercera oleada", que se enmarca en el desenlace de la guerra civil. Con las organizaciones 
creadas en los períodos anteriores se empieza perfilar el actual movimiento de mujeres y a integrar la perspectiva de género en las demandas y denuncias. Asimismo, le empiezan a dar una dimensión regional e internacional al incipiente movimiento dado que, desde su primera participación en los Encuentros Feministas Latinoamericanos y del Caribe en 1987, se hacen presentes en los subsiguientes.

Sexto período: De 1993 a 2005: Fase de transición de posguerra. Este período se abre con la realización en El Salvador del VI Encuentro Feminista Latinoamericano y del Caribe elevándose así su accionar a nivel nacional, regional e internacional. Consolidación del movimiento de mujeres y la perspectiva feminista en EL Salvador y el surgimiento de algunas experiencias organizativas de mujeres rurales.

Sin embargo, en los últimos años se ha debatido en el seno de los movimientos sociales, sin que se discuta sobre el carácter del movimiento de mujeres y la perspectiva feminista en El Salvador, ya que existen dudas acerca de su verdadero papel en el seno de los movimientos sociales y de su impacto social, probablemente como producto de la resistencia a los cambios socioculturales.

Pretendo aportar a este debate mostrando que el movimiento de mujeres tiene actualmente definido su objetivo (visión), su identidad (demandas específicas) y adversario (patriarcado y capitalismo), asumiendo los planteamientos de Manuel Castells quien afirma que "la fuerza y vitalidad del movimiento feminista radica en su diversidad, en su adaptabilidad a las culturas y a las épocas... Además, los movimientos específicos, y las mujeres concretas dentro de ellos, suelen trascender las categorías mezclando identidades, adversarios y objetivos en la definición propia de su experiencia y lucha" (Castells: 1999.224).

De allí que otro reto sea encontrar el núcleo fundamental de la fuerza transformadora del movimiento de mujeres, compartido con los nuevos movimientos sociales en El Salvador, y contribuir así al fomento del pensamiento feminista.

Para efectos de este trabajo Ilamaremos movimiento de mujeres al constituido por todos los espacios organizativos que las mujeres conforman para enfrentar, socializar, reconocer y resolver necesidades e intereses ligados a su condición de género subordinado y discriminado. Se caracterizan por la búsqueda de cambios que mejoren la condición y/o posición de las mujeres en la sociedad. Además se construye y deconstruye permanentemente.

En el transcurrir de los casi veinte años de feminismo en $\mathrm{El}$ Salvador (1986-2006), el movimiento de mujeres lo podemos analizar desde tres ópticas:

a) Movimiento de mujeres es toda y cualquier organización 
de las mujeres en función de intereses específicos o no, sean de pensamiento conservador o progresista. Ejemplos: Organización de Mujeres Sí a la Vida en contra del aborto y de corte fundamentalista; las áreas de la Mujer en cooperativas, gremios y organizaciones no gubernamentales mixtas.

b) Movimiento de mujeres es la organización de las mujeres en función de intereses específicos de género, que están presentes en el barrio, la comunidad, el país y que puede o no estar articulado. Ejemplos: Asociación de Mujeres Rurales del Bajo Lempa (ASMUR), Mesas de Género de la Alcaldía Municipal de San Salvador, Política de Equidad de Género de la Alcaldía de Santa Tecla, Asociación de Mujeres de Oriente, entre otras.

c) Movimiento de mujeres son todas las expresiones organizadas con capacidad para articularse, con altos niveles de organicidad, con capacidad de negociación e interlocución con el Estado y con otros sectores de la sociedad civil y los movimientos sociales; estructurar sus demandas, siendo protagonistas de los cambios sociales y de su condición y posición genérica. Ejemplos: Asociación de Mujeres por la Dignidad y la Vida (Las Dignas,) Movimiento de Mujeres Mélida Anaya Montes (Las Mélidas), Movimiento Sal- vadoreño de Mujeres (MSM), El Instituto de Investigación, Capacitación y Desarrollo de la Mujer (IMU) y la Asociación de Mujeres Flor de Piedra.

Para el logro de sus objetivos es necesario que se den procesos de concientización permanente sobre las relaciones de poder y jerárquicas entre hombres y mujeres. También tener claridad sobre las desigualdades de clase, etnia, raza, preferencia sexual y edad.

Para lograr el análisis y encontrar la conexión del movimiento de mujeres, desde la óptica de la articulación de las organizaciones para la promoción y defensa de los derechos humanos de las mujeres, es necesario actualizar el carácter y el accionar de los nuevos movimientos sociales.

Con el objetivo de iniciar este análisis partimos de la consideración de que el movimiento de mujeres es un movimiento social, dado que ha sido expresión de la acción de las mujeres en procesos históricos y culturales. Lo anterior nos lleva a hacernos algunas preguntas: ¿Se puede caracterizar al movimiento de mujeres como movimiento social? ¿Cuáles son las características teóricas útiles para analizar y definirlo un movimiento social?

Los movimientos sociales tienen ideas básicas que los conforman, cuáles serían las ideas básicas de los movimientos feministas? 
1. Sentimiento de fraternidad/sororidad (del latín soror, sororis, hermana fraterna), se explica por la tendencia de los seres humanos a solidarizarse ante situaciones desfavorables. Para las mujeres podría significar: acopio de potencialidades para el cambio personal y social, esto es, empoderamiento a todo nivel.

2. Discriminación, injusticia básica sentida y vivida en todos los ámbitos de la vida social: económica, política, cultural y por supuesto, sexual. Las mujeres lo han soportado por siglos.

3. Gracias a la acción de las antepasadas, han tenido la posibilidad de mejorar e imaginar un mundo pleno de potencialidades equitativas y armónicas.

4. Los cambios democráticos en la casa y el país, la igualdad, el desarrollo y la paz, la equidad de género, la independencia económica, política y social, para que la mujer pueda obtener derechos individuales y sociales, ostentar derechos iguales a los hombres, acceder al poder para vivir dignamente.

Al movimiento de mujeres, reiteramos, lo consideramos movimiento social, dado que ha sido expresión de la acción de las mujeres en procesos históricos y culturales durante varios siglos. Puede señalarse que el movimiento feminista se ha expresado de manera discontinua ya que ha tenido períodos de auge y retroceso.
Si partimos de que es un movimiento social: se definen como: "acciones colectivas cuyo impacto transforma los valores y las instituciones "(Castells: 1996, 220; Alexis: 1986). Según la tipología clásica de de Alain Touraine, un movimiento social se define mediante tres principios: la identidad del movimiento, el adversario del movimiento y la visión o modelo social del movimiento.

Identidad: que se refiere a la autodefinición del movimiento, de lo que es a nombre de quien se habla. Se habla a nombre de las mujeres salvadoreñas y de ellas mismas como seres humanos. Sabemos que el concepto de identidad es fundamental para la comprensión de un movimiento social, ya que explica por qué los individuos deciden unirse a un movimiento, también depende de los factores de la oportunidad política y de las redes organizacionales.

Adversario: hace referencia al enemigo principal del movimiento según lo identifica éste de forma explícita. El enemigo principal está definido como el sistema patriarcal y aunque no es muy explícito, también, el sistema capitalista o capitalismo patriarcal. Define el núcleo del conflicto: para algunas autoras y autores la noción de "conflicto cultural" es ahora lo medular como lo fueron el conflicto económico de la sociedad industrial y el conflicto político que dominó los primeros siglos de la modernidad.

Visión u objetivo social: se refiere al tipo de orden o de orga- 
nización social que el movimiento desearía obtener en el horizonte histórico. La utopía está basada en la emancipación y propone una nueva ética: la transformación de las relaciones entre los géneros la equidad de género o igualdad de derechos, incluidos los reproductivos, es decir, el desarrollo de valores del movimiento que incluyen el programa y la ideología. El programa es el esquema de cambio que el movimiento propone y la ideología es el cuerpo de ideas que justifican el programa y estrategia del movimiento social.

La construcción de la identidad, la definición del adversario y la claridad de la visión u objetivo social forman parte del proceso de definición del movimiento de mujeres, analizar y explicar dicho proceso forma parte de nuestra investigación.

Se mencionan como experiencias exitosas las siguientes:

1. La Plataforma de Mujeres 1994, ya que a partir de su realización se empezó a configurar el Plan de Acción de Beijing, la conformación del ISDEMU y de la Política Nacional de la Mujer de 1994 a 1997 para ser ejecutad de 1997-2000.

2. La Ley contra la Violencia Intrafamiliar, acompañada de diferentes campañas orientadas a prevenir y erradicar la violencia de género, incluyendo el decreto del 25 de noviembre como Día de la No Violencia contra las Mujeres.
3. El reconocimiento social de la paternidad irresponsable y la vinculación de este reconocimiento a la creación del finiquito moral para todos aquellos que quieran ser elegidos a cargos públicos.

4. La Política Municipal para promover la equidad de Género de la Alcaldía de San Salvador y otras alcaldías como Santa Tecla

\section{Dificultades}

1. El movimiento se ve débil y fragmentario frente al Estado. Hace falta un proyecto propio con estrategias de acción frente a éste. Me parece que las organizaciones de mujeres siguen realizando acciones individuales en el campo de la legislación, salud, poderes locales, etc., pero no hay una estrategia conjunta frente a las políticas estatales. Esto hace que a la larga los resultados de tales esfuerzos sean insuficientes $y$ limitados.

2. Se carece de un proyecto propio, pese a que se han elaborado plataformas conjuntas, en donde se ligue adecuadamente la problemática específica de las mujeres con la problemática nacional, dentro del marco del problema estructural que vivimos en El Salvador.

3. Por ejemplo, una debilidad de las plataformas es que se plantean demandas en una sola dirección de lo que se quiere que el Estado haga a favor de las 
mujeres, pero no en la dirección de lo que las mujeres deben hacer en la vida cotidiana para la transformación de la sociedad.

4. Considero que hace falta enfatizar en la problemática de las mujeres en el mundo privado para deconstruir la tradicional división sexual del trabajo doméstico, lo cual debería contemplarse en las plataformas políticas.

\section{Referencias bibliográficas}

- Aguilar, Ana Leticia; Blanca Estela Dole, Morena Herrera, Sofía Montenegro, Lorena Camacho y Lorena Flores (1997) Movimiento de mujeres en Centroamérica. Programa Regional La Corriente/Fundación Buntstift: Managua.

- Alexis, Boris (1986) Movimientos sociales y cambio social._Asociación de Investigación, Trabajo y Estudios Sociales A.C., Bogotá.

- Castells, Manuel (1999). "La Era de la Información” en El poder de la identidad. Volumen II, Tercera Edición, Siglo XXI, México.

- De Piero, Sergio. Organizaciones de la sociedad civil. Tensiones de una agenda en construcción, Paidós, Buenos Aires, 2005.

- Menjívar, Rafael y Camacho, Daniel (Coords.) (1985)._Movimientos populares en Centroamérica, EDUCA, San José.
- Molineux, Maxine (2003) Movimientos de Mujeres en América Latina. Estudio teórico comparado. Ediciones Cátedra, Universidad de Valencia, España.

- Navas, María Candelaria (1987) Las organizaciones de mujeres en $\mathrm{El}$ Salvador 1975-1985. Tesis de maestría en Estudios Latinoamericanos, Universidad Nacional Autónoma de México, UNAM: México D.F.

- Navas, María Candelaria (2006) El Movimiento de mujeres en El Salvador 1986-2005. Avance de tesis de doctorado en Ciencia Política UNAM.

- PNUD. (2004) La equidad de género en El Salvador, San Salvador.

- Touraine, Alain (1998). ¿Podremos vivir juntos? Iguales $y$ diferentes. Fondo de Cultura Económica, Buenos Aires.

\section{Notas}

1 Utilizaremos la palabra”oleada”, parafraseando a autoras como Amelia Valcárcel, que lo usa en el artículo "La memoria colectiva y los retos del feminismo", en Los desafíos del feminismo ante el siglo XXI, Instituto Andaluz de la Mujer, España, 2005 y a D’Atri, Andrea: "Feminismo latinoamericano. Entre la insolencia de las luchas populares y la mesura de la institucionalización” en Creatividad feminista s/f. Según el Diccionario de la lengua española, oleada se define como "ola grande; embate y golpe de ola// movimiento impetuoso de mucha gente apiñada". 